\title{
EFEITO DA DOSE DE URÉIA E PERÍODO DE TRATAMENTO SOBRE A COMPOSIÇÃO DO FENO DE PASPALUM NOTATUM
}

\author{
EFFECT OF THE LEVEL OF UREA AND PERIOD OF TREATMENT \\ ON COMPOSITION OF PASPALUMNOTATUMHAY
}

Pádua, F.T. ${ }^{*}$, Almeida, J.C.C. ${ }^{2}$, Nepomuceno, D.D. ${ }^{3}$, Cabral Neto, O. ${ }^{4}$ e Deminicis, B.B. ${ }^{5}$

1Universidade Estadual do Norte Fluminense. Laboratório de Zootecnia e Nutrição Animal. Campos dos Goytacazes, RJ. CEP 28013-612. Brasil. *ftpadua@uenf.br

${ }^{2}$ Universidade Federal Rural do Rio de Janeiro. Departamento de Nutrição Animal e Pastagens. Seropédica, RJ. Brasil.

${ }^{3}$ Escola Superior de Agricultura Luiz de Queiroz. Universidade de São Paulo. Piracicaba, SP. Brasil. ${ }^{4}$ Faculdade de Ciências Agro-Ambientais. Avenida Brasil. Penha. Rio de Janeiro, RJ. Brasil.

${ }^{5}$ Universidade Estadual do Norte Fluminense. Laboratório de Fitotecnia. Campos dos Goytacazes, RJ. Brasil.

\section{PalaVRas chaVe adicionais}

Amonização. Conservação de forragem. Gramínea. Valor nutritivo.

\section{RESUMO}

Avaliou-se os efeitos das doses de uréia e períodos de tratamento sobre os teores de proteína bruta (PB), fibra em detergente neutro (FDN), fibra em detergente ácido (FDA), hemicelulose (HCEL) e matéria mineral (MM) do feno de gramabatatais (Paspalum notatum). Foram utilizadas doses de 0 (tratamento controle); 0,5; 1,0; 1,5; 2,0 e $2,5 \%$ de uréia com base na matéria natural e períodos de armazenamento de 21,28 e 35 dias. O experimento foi conduzido segundo um delineamento inteiramente casualizado num desenho em parcela subdividida, com os períodos casualizados na parcela e as doses na subparcela. Não foi observado efeito de interação entre a dose e o período de armazenamento $(p>0,05)$. Para o teor de proteína bruta, fibra em detergente neutro, fibra em detergente ácido, hemicelulose foi observado efeito de regressão $(p<0,05)$ em função das doses de uréia aplicadas. Para o conteúdo de matéria mineral não foi evidenciado efeito de regressão. As doses de uréia aplicadas proporcionaram melhorias no tocante à redução dos constituintes da parede celular, porém, os períodos de armazenamento estudados não influenciaram o comportamento das variáveis analisadas.

Recibido: 23-7-08. Aceptado: 2-4-09.

\section{AdDitional KeYWORDS}

Ammonization. Forage conservation. Grass. Nutritional value.

\section{SUMMARY}

This study was conducted to evaluate the effects of doses of urea and periods of treatment on the crude protein (PB), neutral detergent fiber (FDN), acid detergent fiber (FDA), hemicellulose (HCEL) and mineral matter (MM) of hay of Paspalum notatum. Were used levels of 0 (control treatment), $0.5,1.0,1.5,2.0$ and $2.5 \%$ of urea based on natural matter and storage periods of 21,28 and 35 days. The experiment was conducted in a completely randomized design in a design in a split plot, with those randomized in the plot and the doses in the sub-plot. There was no effect of interaction between level and the period of storage $(p>0.001)$ for the variables. For the content of FDN, FDA, HCEL and PB the regression effect was observed $(p<0.001)$ depending on the dose of urea applied. For the content of MM was not evident effect of regression. The level of urea applied provided improvements with respect to the reduction of cell wall constituents, however, the storage periods studied did not influence the behavior of variables.

\section{INTRODUÇÃO}

A sazonalidade de produção forrageira provocada por mudanças nas condições 


\section{PÁDUA, ALMEIDA, NEPOMUCENO, CABRAL NETO E DEMINICIS}

climáticas de cada estação do ano, (primavera, verão, outono e inverno), como queda de temperatura, redução do fotoperíodo e ausência de chuvas, promove déficits quantitativos e qualitativos na forragem produzida nas pastagens.

Diante da necessidade de atender as exigências alimentares dos animais, produtores e técnicos lançam mão de formas de manejo das pastagens reservando-as para o período de escassez de forragens, com a mesma finalidade são formadas capineiras e canaviais. Porém, as principais formas de conservação de forragens (feno e silagem) são comumente adotadas como forma de prevenção para estação seca. Por outro lado, a indisponibilidade de forragens de qualidade para confecção de silagem ou feno apresenta-se como fator limitante para garantir os índices de produtividade ou mesmo a mantença do animal.

Diversos métodos têm sido testados visando melhorar o aproveitamento de forragens de baixa qualidade, tais como: tratamentos físicos, químicos ou biológicos, suplementação ou combinação de dois ou mais destes. Embora todos esses processos sejam tecnicamente possíveis, muitos são economicamente inviáveis nas condições brasileiras. Dentre os tratamentos químicos avaliados, principalmente com palhas ou resíduos de culturas e, mais recentemente, com fenos, destaca-se o uso da amônia anidra $\left(\mathrm{NH}_{3}\right)$ ou da uréia, processo denominado de amonização.

Um dos primeiros parâmetros estudados no processo de amonização de volumosos foi o efeito das doses de amônia aplicadas (Garcia e Pires, 1998). De acordo com Sundstol e Coxworth (1984) vários fatores podem afetar a eficiência da amonização, destacando-se a quantidade aplicada, o período de tratamento e a umidade da forragem.

A capacidade de substâncias químicas auxiliarem no processo de conservação de forragens no controle de microrganismos como fungos, bactérias, mofos e bolores que provocam a redução do valor nutritivo da forragem consumindo os carboidratos solúveis disponíveis e aumentando os carboidratos estruturais é abordada por diversos autores. Por outro lado, a solubilização dos constituintes da parede celular vegetal é um efeito positivo de algumas substancias químicas utilizadas no tratamento de forragens de baixa qualidade uma vez que eleva o valor nutritivo do alimento a ser fornecido aos animais.

A eficiência de um produto está relacionada com a quantidade a ser aplicada, o material a ser tratado e as condições de armazenamento durante o período de tratamento. Entretanto, quando são utilizados diferentes materiais faz-se necessário além da observância dos resultados divulgados na literatura científica, testes com diferentes quantidades e períodos de tratamento a fim de se obter a melhor combinação dos fatores avaliados.

O objetivo do presente experimento foi avaliar a influência de doses de uréia e períodos de armazenamento sobre a composição químico bromatológica do feno de grama-batatais.

\section{MATERIAL E MÉTODOS}

O presente experimento foi conduzido no Setor de Forragicultura e Pastagens do Departamento de Nutrição Animal e Pastagem do Instituto de Zootecnia da Universidade Federal Rural do Rio de Janeiro (DNAP/IZ/UFRRJ), localizado no município de Seropédica, na região da baixada fluminense do estado do Rio de Janeiro, situado a uma latitude de $22^{\circ} 45^{\prime} \mathrm{S}$, longitude $43^{\circ} 41^{\prime} \mathrm{W}$, com uma altitude média de 33 metros. O clima da região é do tipo $\mathrm{AW}$, pela classificação de Köppen.

A região apresenta duas estações distintas, uma seca, que se estende de abril a setembro e outra quente e chuvosa, que se estende de outubro a março. Levantamentos dos últimos dez anos mostram precipitação média anual de $1281,7 \mathrm{~mm}$. As temperaturas 
médias anuais máximas e mínimas são respectivamente $29,8^{\circ} \mathrm{Ce} 20,1^{\circ} \mathrm{C}$.

O corte da grama (Paspalum notatum) foi efetuado por roçadeira acoplada a trator regulada para corte a uma altura aproximada do solo de $10 \mathrm{~cm}$. Após o corte o material foi desidratado durante 72 horas, sendo realizados os processos de enleiramento e desenleiramento, com o objetivo de acelerar e uniformizar a desidratação, em seguida o feno foi recolhido e transportado para as dependências do DNAP/IZ, para aplicação da uréia. Foram aplicadas as seguintes doses: 0 (controle); 0,$5 ; 1,0 ; 1,5 ; 2,0$ e 2,5\%, com base na matéria natural. O período de desidratação do feno foi estabelecido através de análise sensorial onde se avaliou a plasticidade do material e a umidade aparente. O material foi pesado na quantidade de 4 $\mathrm{kg}$ feno/saco sendo acondicionado por camadas e a uréia aplicada simultaneamente, foram utilizados sacos plásticos com capacidade para 10 litros. No momento da aplicação o feno apresentava $83 \%$ de MS. Foram testados três períodos de armazenamento 21,28 e 35 dias. No momento do corte as plantas estavam com 21 dias de crescimento.

A uréia foi distribuída sobre a forragem previamente pesada acondicionada em sacos plásticos e misturada para obter uma maior homogeneização em seguida os sacos plásticos foram vedados de modo a impedir a perda da uréia aplicada por volatilização na forma de amônia. Após os períodos de armazenamento os sacos foram abertos permanecendo por 24 horas para eliminação da amônia produzida pela hidrólise da uréia, em seguida retirou-se uma amostra de cada parcela experimental. As amostras foram pesadas e colocadas em estufa de ventilação forçada de ar a $55^{\circ} \mathrm{C}$ durante 72 horas pesadas posteriormente para determinação do teor de MS.

As amostras foram moídas em moinho de facas do tipo Willey equipado com peneira para obtenção de partículas com granulometria de $1 \mathrm{~mm}$. As amostras foram analisadas quanto aos teores de PB, FDN, FDA, MM segundo Silva e Queiroz (2002). Os teores de hemicelulose foram obtidos pela diferença entre FDN e FDA. Os tratamentos foram distribuídos segundo um delineamento inteiramente casualizado em esquema de parcelas subdivididas, contendo: 3 (períodos) x 6 (doses) e 3 (repetições). Os períodos testados foram casualizados nas parcelas e as doses nas sub-parcelas, sendo os dados analisados por regressão utilizando o programa estatístico SISVAR (Ferreira, 1999).

\section{RESULTADOSEDISCUSSÃO}

A composição química do feno de grama-batatais tratado com diferentes doses de uréia e períodos de armazenamento é apresentada na tabela I. Não foi observado efeito de interação entre os fatores testados, dose de uréia e período de armazenamento. Os períodos de armazenamento não influenciaram significativamente $(\mathrm{p}>0,05)$ o comportamento das variáveis analisadas.

Os teores de FDN e FDA reduziram linearmente $(p<0,001)$ em função dos níveis de uréia (tabela I), possivelmente pelo fato de que, quando materiais fibrosos são tratados com produtos alcalinos, como a uréia, as ligações intermoleculares, mais especificamente as pontes de hidrogênio, entre as moléculas de celulose se rompem, solubilizando parte deste componente da parede celular (Van Soest, 1994). Gobbi et al. (2005) observaram comportamento semelhante para a variável FDA e efeito quadrático para FDN no feno de Brachiaria decumbens tratado com uréia. Segundo Klopfenstein (1978), a redução no conteúdo de FDA nos materiais amonizados está associada à solubilização de lignina e celulose, presumidamente como um resultado da redução da cristalinidade da celulose e também em razão de sua expansão e da saponificação das ligações éster entre lignina e hemicelulose. Estes resultados corroboram os obtidos por Reddy 
Tabela I. Valores médios (\% de MS) de fibra em detergente neutro (FDN), fibra em detergente ácido (FDA), hemicelulose (HCEL), matéria mineral (MM) e proteína bruta (PB) do feno de grama batatais tratado com uréia e armazenado nos períodos de 21, 28 e 35 dias. (Average values (\% of MS) of neutral detergent fiber (FDN), acid detergent fiber (FDA), hemicellulose (HCEL), mineral matter (MM) and crude protein (PB) of hay of Paspalum notatum treated with urea and stored in periods of 21,28 and 35 days).

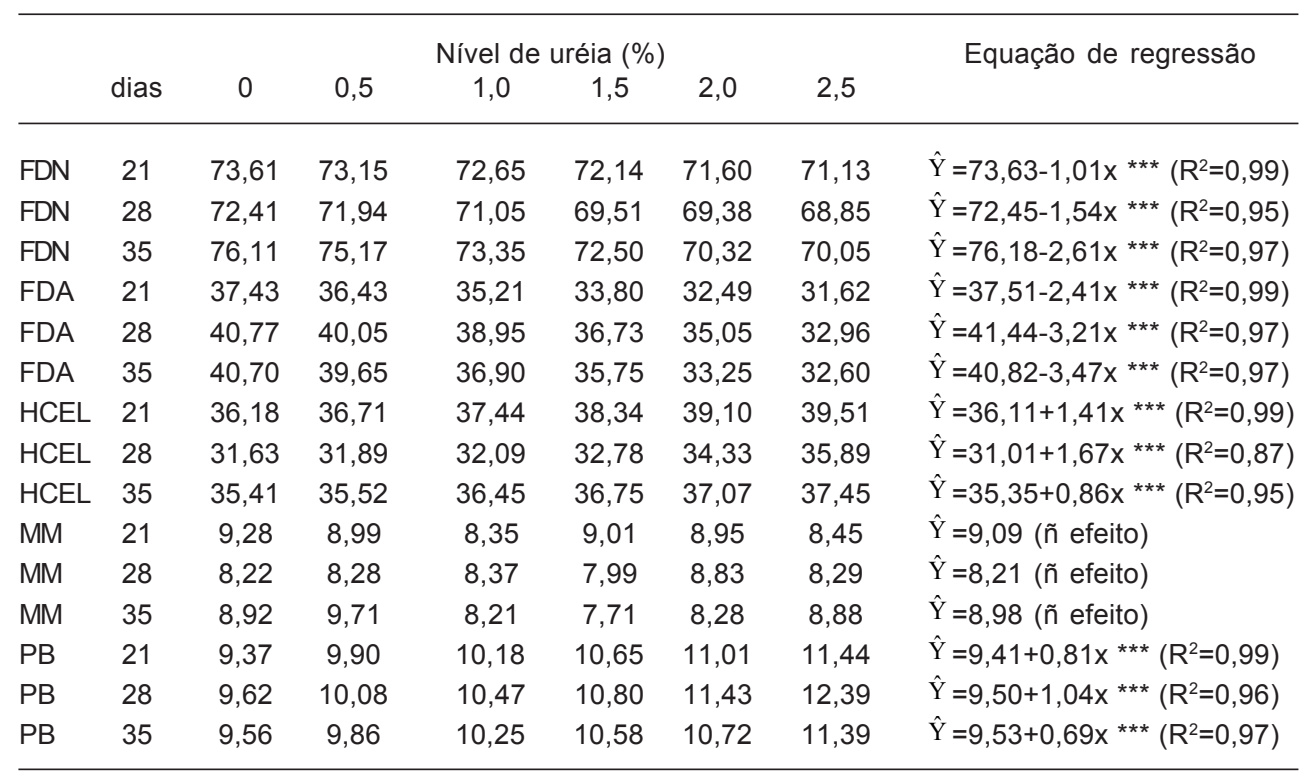

${ }^{* * *} p<0,01$ pelo Teste $t$.

et al. (1993), Hai e Singh (1994) e Leal et al. (1994), que observaram redução nos teores de FDA de feno de sorgo, palhada de aveia e palhada de sorgo, respectivamente, tratados com fontes de amônia. Fahmy e Klopfenstein (1994), Leal et al. (1994) e Shen et al. (1998) também relataram declínio no teor de celulose de volumosos amonizados.

A amônia produto da decomposição da uréia pode agir sobre as moléculas de hemicelulose, promovendo o rompimento de ligações e a solubilização parcial deste componente, facilitando a ação dos microrganismos ruminais sobre a parede celular (Klopfenstein, 1978). Além disso, existe a possibilidade de a amônia promover o rompimento das pontes de hidrogênio entre as moléculas de celulose, promovendo sua solubilização parcial (Van Soest, 1994), e entre as moléculas de celulose e hemicelulose, permitindo hidratação mais rápida e eficiente da parede celular, facilitando o acesso dos microrganismos ruminais e aumentando a digestão (Berger et al., 1994). Ressalta-se que, neste estudo, a elevação das doses de uréia resultou em redução dos constituintes da parede celular vegetal FDN e FDA promovida pela solubilização dos mesmos, o que, provavelmente, resultaria em incremento no conteúdo de carboidratos prontamente digestíveis (Van Soest, 1994).

Reis et al. (2001a), utilizaram 3,0\% de amônia anidra e 5,4\% de uréia com base no peso seco dos fardos de feno de Brachiaria decumbens, B. brizantha e Hyparrhenia rufa, observaram tanto no material tratado com amônia anidra ou com uréia, decréscimos 
de 6,0 e 4,1 unidades percentuais nos teores de FDN e de 5,9 e 3,5 nos de hemicelulose dos fenos avaliados.

Os teores de hemicelulose, por terem sidos obtidos pela diferença entre FDN e FDA apresentaram reduções em função das doses de uréia aplicadas e comportaram-se de forma crescente. Gobbi et al. (2005) não observaram efeito de níveis de uréia sobre os teores de hemicelulose, estimando-se valor médio de $37 \%$. No entanto, boa parte dos estudos sobre a amonização com uréia tem registrado diminuição nos teores dessa fração da parede celular (Brown e Adjei, 1995; Rosa et al., 1998; Reis et al., 2001b). Segundo os autores este comportamento pode ser resultante do fato de a hemicelulose ter sido calculada a partir da diferença entre os teores de FDN e FDA, uma vez que as curvas de redução de FDN e FDA apresentaram comportamento diferenciado (quadrático e linear, respectivamente) em relação aos tratamentos com uréia.

O conteúdo de PB do feno de gramabatatais foi linearmente elevado em função do aumento da dose de uréia aplicada comportamento que pode ser explicado pela deposição do nitrogênio não proteico (NNP) aplicado na forma de uréia no tecido vegetal. Da mesma forma, Pires et al. (1999) avaliaram a amonização da quirera de milho com alta umidade e observaram que o teor de PB aumentou com os crescentes níveis de amônia. No mesmo sentido, Candido et al. (1999) observaram diferença de 11,8\% para os teores de PB entre a maior dose e o tratamento controle para o bagaço de canade-açúcar amonizado com uréia.

O conteúdo de MM do feno não foi alterado em função das doses de uréia aplicadas, o que pode ser explicado pelo fato da uréia ser hidrolisada pela urease em amônia,

\section{BIBLIOGRAFIA}

Berger, L.L., Fahey Jr., G.C., Bourquim, L.O. and Titgemeyer, E.C. 1994. Modification of forage quality after harvest. In: Fahey Jr., G.C. (ed). composto volátil não se acumulando no material tratado. Lopes et al. (2005) observaram elevação do conteúdo de matéria mineral na palma forrageira em função do aumento da dose de uréia aplicada tendo os autores observado efeito quadrático para esta variável. Entretanto, Rosa et al. (2000) testaram o efeito da associação de doses de uréia com níveis de umidade na composição química do feno de Brachiaria brizantha cv. marandu e verificaram comportamento inconsistente para explicar o efeito dos fatores sobre o teor de matéria mineral, onde os referidos autores observaram para o feno com $20 \%$ de umidade tratado com doses de 2,4 e $6 \%$ de uréia na base da matéria seca redução dos níveis de MM de forma linear, já para o teor de umidade de $30 \%$ combinado com as doses de uréia anteriormente citadas os autores observaram comportamento quadrático passando por um ponto de máximo e para o teor de umidade de $40 \%$ foi observado efeito de regressão linear verificando-se elevação do teor de MM em função do aumento da dose de uréia. Diante do exposto, o efeito da amonização sobre o conteúdo de matéria mineral do material tratado apresenta-se como ponto de controversa entre diferentes autores.

\section{CONCLUSÕES}

Os constituintes da parede celular vegetal foram significativamente alterados pela amonização com redução dos teores de FDN e FDA.

O conteúdo de $\mathrm{PB}$ foi elevado em função do aumento da dose de uréia aplicada.

Os períodos de armazenamento não influenciaram as variáveis analisadas.

O tratamento com uréia do feno de grama batatais proporcionou melhoria no valor nutricional do feno de grama-batatais.

Forage quality, evaluation and utilization. Amer. Soc. Agron., 1: 922-966.

Brown, W.F. and Adjei, M.B. 1995. Urea 


\section{PÁDUA, ALMEIDA, NEPOMUCENO, CABRAL NETO E DEMINICIS}

ammoniation effects on the nutritive value of Guineagrass (Panicum maximum) hay. J. Anim. Sci., 73: 3085-3093.

Cândido, M.J.D., Neiva, J.N.M., Pimentel, J.C.M., Vasconcelos, V.R., Sampaio, E.M. e Mendes Neto, J. 1999. Avaliação do valor nutritivo do bagaço de cana-de-açúcar amonizado com uréia. Rev. Bras. Zootecn., 28: 928-935.

Fahmy, S.T.M. and Klopfenstein, T.J. 1994. Treatment with different chemicals and their effects on the digestibility of maize stalks. 2 . Intake and in vivo digestibility as affected by chemical treatment and monensin supplementation. Anim. Feed Sci. Technol., 45: 309-316.

Ferreira, D.F. 1999. SISVAR 4.3. Sistema de análises estatísticas. CD-ROM. Universidade Federal de Lavras, UFLA. Lavras, MG.

Garcia, R. e Pires, A.J.V. 1998. Tratamento de volumosos de baixa qualidade para utilização na alimentação de ruminantes. Em: Congresso Nacional dos Estudantes de Zootecnia. Anais... AMEZ. Viçosa. pp. 33-60.

Gobbi, K.F., Garcia, R., Garcez Neto, A. F., Pereira, O.G., Bernardino, F.S. e Rocha, F.C. 2005. Composição química e digestibilidade in vitro do feno de Brachiaria decumbens Stapf. tratado com uréia. Rev. Bras. Zootecn., 34: 720-725.

Hai, N.V. and Singh, G.P. 1994. Effect of ammoniation through urea treatment of oat straw on the rumen degradability of fibre. Indian $\mathrm{J}$. Dairy Sci., 47: 176-180.

Klopfenstein, T.J. 1978. Chemical treatment of crop residues. J. Anim. Sci., 46: 841-848.

Leal, M., Shimada, A. and Hernández, E. 1994. The effect of $\mathrm{NH}_{3}$ and/or $\mathrm{SO}_{2}$ on the compositional and histological characteristics of sorghum stover. Anim. Feed Sci. Technol., 47: 141-150.

Lopes, J.S., Jaeger, S.M.P.L., Tavares, J.T.Q., Silva, A.M. e Ledo, C.A.S. 2005. Composição bromatológica de palma forrageira (Nopalea coccinellifera Salm Dyck) amonizada. Magistra, 17: 107-113.

Pires, A.J.V., Garcia, R., Cecon, P.R., Neiva, J.N.M. e Sarmento, P. 1999. Amonização da quirela de milho com alta umidade. Rev. Bras. Zootecn. 28: 1186-1193.

Reddy, D.V., Ramachandra Reddy, R. and Subra Reddy, K.V. 1993. Effect of urea-ammoniation of moist sorghum hay chemical composition and degradation kinetics. Indian J. Dairy Sci., 46: 45-48.

Reis, R.A., Rodrigues, L.R.A., Pereira, J.R.A. e Ruggieri, A.C. 2001a. Composição química e digestibilidade de fenos tratados com amônia anidra ou uréia. Rev. Bras. Zootecn., 30: 666673.

Reis, R.A., Rodrigues, L.R.A., Resende, K.T., Pereira, J.R.A. e Ruggieri, A.C. 2001b. Avaliação de fontes de amônia para o tratamento de fenos de gramíneas tropicais. 1. Constituintes da parede celular, poder tampão e atividade ureática. Rev. Bras. Zootecn., 30: 674-681.

Rosa, B., Souza, H. e Rodrigues, K.F. 2000. Composição química do feno de Brachiaria brizantha cv. marandu tratado com diferentes proporções de uréia e de água. Ciência Anim. Bras., 1: 107-113.

Rosa, B., Reis, R.A., Resende, K.T., Kronka, S.N. e Jobim, C.C. 1998. Valor nutritivo do feno de Brachiaria decumbens Stapf. cv. basilisk submetido a tratamento com amônia anidra $e$ uréia. Rev. Bras. Zootecn., 27: 815-822.

Shen, H.S., Ni, D.B. and Sundstol, F.E. 1998. Studies on untreated and urea-treated rice straw from three cultivation seasons: 1. Physical and chemical measurements in straw and straw fractions. Anim Feed Sci. Technol., 73: 243261.

Silva, D.J. e Queiroz, A.C. 2002. Análise de alimentos (métodos químicos e biológicos). $2^{\mathrm{a}}$ ed. UFV. Viçosa. $165 \mathrm{pp}$.

Sundstol, F.E. and Coxworth, E.M. 1984. Ammonia tratament. In: Sundstol, F.E. and E. Owen. Straw and others fibrous by-products as feed. Elsevier Press. Amsterdam. pp. 196-247.

Van Soest, P.J. 1994. Nutritional ecology of the ruminant. Cornell University Press. Ithaca. 476 pp.

Archivos de zootecnia vol. 60, núm. 229, p. 62. 